\title{
Safety of coronary revascularization deferral based on fractional flow reserve and instantaneous wave- -free ratio in patients with chronic kidney disease
}

\author{
Alejandro Travieso®, Alex Fernando Castro-Mejía, Adrián Jerónimo-Baza, \\ María José Pérez-Vizcayno, Hernán Mejía-Rentería, Fernando Macaya, \\ Gabriela Tirado-Conte, Luis Nombela, Pilar Jiménez-Quevedo, Pablo Salinas, \\ Iván J. Núñez-Gil, Antonio Fernández-Ortiz, Javier Escaned, Nieves Gonzalo \\ Hospital Clínico San Carlos, Madrid, Spain
}

\begin{abstract}
Background: The safety of revascularization deferral according to pressure wire examination in $p a-$ tients with chronic kidney disease (CKD) has not been fully established.

Methods: From a retrospective cohort of 439 patients in whom revascularization was deferred after physiological assessment, we examined the incidence of patient-oriented composite endpoint (POCE: all-cause death, myocardial infarction [MI] and unplanned revascularization) in patients with CKD (estimated glomerular filtration rate $[e G F R]<60 \mathrm{~mL} / \mathrm{min} / 1.73 \mathrm{~m}^{2}$ ) and without it.

Results: At 4 years of follow-up, the primary endpoint was met by $25.0 \%$ of patients with CKD and by $14.4 \%$ of patients without CKD (hazard ratio [HR] 1.56, 95\% confidence interval [CI] 0.96-2.53, $p=0.071$ ). The incidence of POCE was even higher in patients with an eGFR $<30 \mathrm{~mL} / \mathrm{min} / 1.73 \mathrm{~m}^{2}$ : 43.8\% (HR 3.10, 95\% CI 1.08-8.92, $p=0.036$ ). However, no differences were observed in the incidence of $M I$ ( $4.2 \%$ vs. $4.4 \%$ in non-CKD), target vessel revascularization (5.8\% vs. $5.9 \%)$, and target vessel MI $(0.8 \%$ vs. $4.6 \%)$.

Conclusions: Patients with CKD in whom pressure-wire evaluation led to deferral of coronary revascularization develop more POCE in the long term, compared to patients with normal renal function. However, the increase in POCE in patients with CKD was seldom related to deferred vessels, thus suggesting an epiphenomenon of an intrinsically higher cardiovascular risk of CKD patients. (Cardiol J 2022, 29, 4: 553-562)
\end{abstract}

Key words: pressure wire, fractional flow reserve, instantaneous wave-free ratio, chronic kidney disease

\section{Introduction}

Physiological evaluation of coronary stenosis is a valuable tool to guide myocardial revascularization. Its safety has been widely demonstrated in the past years [1], shifting the process of treating coronary lesions from anatomical to physiological grounds. For more than two decades fractional flow reserve (FFR) was the only pressure-derived index available for functional stenosis assessment. More recently, instantaneous wave-free ratio (iFR), a non-hyperemic diastolic pressure ratio that overcomes some limitations of FFR [2,3], was demonstrated to be non-inferior to FFR in clinical decision-making, contributing to more widespread use of pressure wire interrogation in real practice [4].

Address for correspondence: Dr. Nieves Gonzalo, Hospital Clínico San Carlos, Madrid, Spain, C/Profesor Martin Lagos, s/n. 28040, tel: +34 620920 297, e-mail: nieves_gonzalo@yahoo.es

Received: 1.12.2020 Accepted: 26.02.2021 Early publication date: 10.01.2021

This article is available in open access under Creative Common Attribution-Non-Commercial-No Derivatives 4.0 International (CC BY-NC-ND 4.0) license, allowing to download articles and share them with others as long as they credit the authors and the publisher, but without permission to change them in any way or use them commercially. 
One of the ways that pressure guidewire interrogation contributes to improved patient outcome is by avoiding unneeded revascularization procedures in functionally non-significant coronary stenoses. While the overall safety of myocardial revascularization deferral based on FFR and iFR has been well stablished $[5,6]$, there is a paucity of data regarding such an approach in subgroups of patients with high risk of coronary disease progression. One such subgroup is made up of patients with chronic kidney disease (CKD), which is associated with a higher burden of coronary atherosclerosis [7], faster disease progression [8], and higher incidence of cardiovascular events, compared with patients with normal renal function $[9,10]$.

The main aim of this study was to investigate whether deferral of coronary stenosis revascularization based on pressure guidewire interrogation is equally safe in patients with CKD and in patients with normal function. Additionally, we also wanted to investigate the long-term outcomes of revascularization deferral based on FFR or iFR in patients with and without CKD.

\section{Methods}

\section{Study design and population selection}

This is a single-center, retrospective study that collected all consecutive patients who underwent pressure-wire evaluation of angiographical stenosis (by visual estimation), and in whom treatment was deferred based on the result of this technique. Either FFR or iFR were performed, and patients were classified as FFR-deferred or iFR-deferred according to the method of pressure wire used for evaluation.

Different baseline characteristics were assessed. Serum creatinine was determined from blood samples in the 48 hours prior to the procedure. The estimated glomerular filtration rate (eGFR) was derived using the CKD-EPI formula. The cut-off value of $60 \mathrm{~mL} / \mathrm{min} / 1.73 \mathrm{~m}^{2}$ was used to establish the presence or absence of CKD. Current clinical practice guidelines were used to define the different CKD stages [11].

\section{Procedural aspects}

Pressure wire assessment was performed with commercial guidewires available during the study period - Verrata (Phillips Healthcare, San Diego, California) and PressureWire X (St. Jude Medical, St. Paul, Minnesota) - and a standard technique as previously reported. An intracoronary bolus of nitrates $(200 \mu \mathrm{g})$ was administered before FFR or iFR measurement. In cases in which FFR was performed, intravenous adenosine was infused with a rate of $140 \mu \mathrm{g} / \mathrm{kg} / \mathrm{min}$. At the end of each procedure, the presence of significant drift was ruled-out by placing the sensor of the pressure-wire at the tip of the guiding catheter.

In patients with stable angina, physiological evaluation was performed in the same procedure and all intermediate stenoses could be assessed. Serial stenoses were assessed as a single lesion and only those with non-ischemic values of pressure wire examination were deemed for inclusion in the present analysis. In patients with acute coronary syndromes, interrogation with a pressure wire was performed at a staged procedure only in non-culprit vessels. The cut-off points to defer revascularization were FFR $>0.80$ or iFR $>0.89$.

\section{Endpoints}

The primary endpoint was the combination of all-cause death, myocardial infarction (MI), or unplanned revascularization. Secondary endpoints were all-cause death, death due to cardiovascular causes, MI, and unplanned revascularization. Moreover, vessel-related endpoints such as target vessel MI and target vessel revascularization (TVR) were pre-specified as secondary endpoints. The minimum follow-up period was 2 years.

\section{Statistical analysis}

The population was divided based on the presence or absence of CKD, and the technique of pressure wire was used to defer revascularization (FFR or iFR).

Univariate analysis for baseline characteristics was done using the Pearson $\chi^{2}$ test or Fisher's exact test for categorical variables, as appropriate. Comparison between continuous data was made using the Student-Fisher t-test or Wilcoxon's rank test in cases of non-normal distributions.

For the primary and secondary endpoints, a time-to-event analysis was performed using the Cox's proportional hazards model. Results are reported as hazard ratios (HR) with two-sided 95\% confidence intervals (CI). Analyses were performed in an unadjusted manner as well as being adjusted by variables that were considered relevant: age, sex, the presence of diabetes mellitus, hypertension, tobacco use, clinical presentation, and the percentage of angiographic diameter stenosis.

The validity of the proportional hazards assumption was assessed using Schoenfeld residuals. No signs of violation of the proportional hazards 


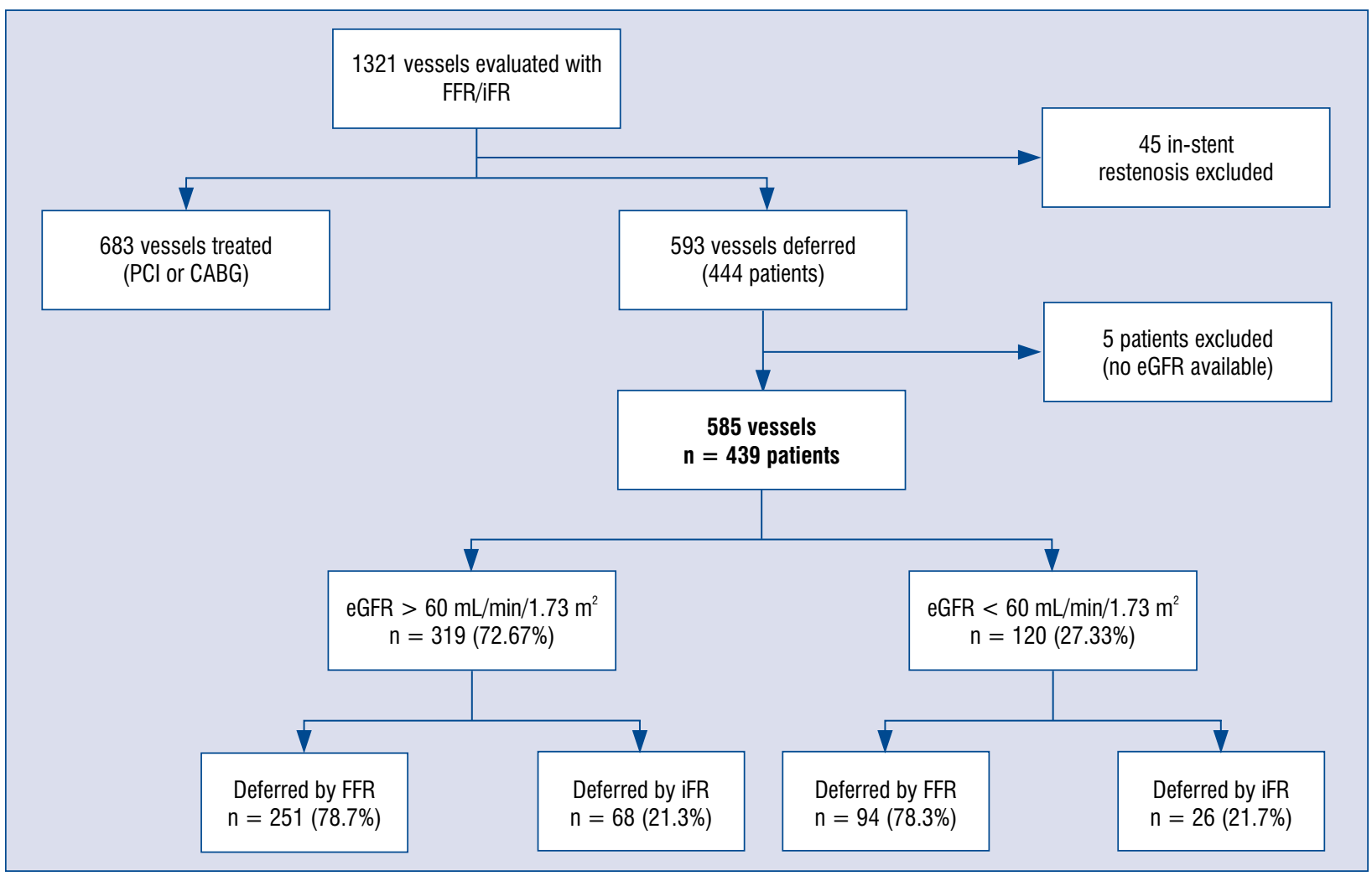

Figure 1. Flowchart of the study; CABG - coronary artery bypass grafting; FFR — fractional flow reserve; iFR — instantaneous wave-free ratio; eGFR - estimated glomerular filtration rate; $\mathrm{PCI}$ - percutaneous coronary intervention.

principle were found. Finally, cumulative hazards curves were created using the Kaplan-Meier method.

All statistical calculations were carried out with STATA 14 (StataCorp. 4905 Lakeway Drive. College Station, Texas. USA).

\section{Results}

\section{Study population}

From January 2012 to December 2016, a total of 1321 vessels underwent pressure-wire evaluation. From them, a total of 593 vessels (444 patients) were deferred according to the result of the pressure wire assessment. Five patients were excluded because of the unavailability of renal function data. A final cohort of 439 patients was included in the analysis (Fig. 1).

\section{Baseline characteristics}

Of the overall population, 120 (27.3\%) patients had an eGFR of less than $60 \mathrm{~mL} / \mathrm{min} / 1.73 \mathrm{~m}^{2}$. Sixteen of them $(3.6 \%)$ had severe eGFR impairment
( $<30 \mathrm{~mL} / \mathrm{min} / 1.73 \mathrm{~m}^{2}$ or hemodialysis). Baseline characteristics are shown in Table 1.

Patients with eGFR $<60 \mathrm{~mL} / \mathrm{min} / 1.73 \mathrm{~m}^{2}$ were significantly older ( 73.5 years vs. 66.6 years, $\mathrm{p}<0.001$ ) and had a higher prevalence of cardiovascular risk factors such as hypertension $(79.2 \%$ vs. $69.9 \%, \mathrm{p}=0.053)$, diabetes mellitus (50.8\% vs. $31.7 \%, \mathrm{p}<0.001$ ), and peripheral vascular disease $(16.7 \%$ vs. $5.6 \%, \mathrm{p}<0.001)$. They had higher rates of anticoagulation treatment $(16.7 \%$ vs. $6.3 \%$, $\mathrm{p}=0.003$ ) and less use of acetylsalicylic acid (ASA; $89.1 \%$ vs. $95.8 \%, \mathrm{p}=0.008$ ).

Baseline angiographical characteristics and physiological results are shown in Table 2. Patients had a mean of 1.3 vessels interrogated in both groups. No differences were found in the mean values of FFR or iFR in either group, or in the type of vessel evaluated, the left anterior descendant (LAD) being the most frequently assessed. A less than $1 \%$ but statistically significant difference was seen in the percentage of angiographic stenosis $(61.0 \%$ vs. $59.1 \%, p=0.027)$, but this small disparity can be considered as clinically not relevant. 
Table 1. Baseline characteristics.

\begin{tabular}{|c|c|c|c|}
\hline & $\begin{array}{c}\text { No CKD (eGFR > } 60 \mathrm{~mL} / \\
\left./ \mathrm{min} / 1.73 \mathrm{~m}^{2}\right)\end{array}$ & $\begin{array}{c}\text { CKD (eGFR }<60 \mathrm{~mL} / \\
\left./ \mathrm{min} / 1.73 \mathrm{~m}^{2}\right)\end{array}$ & $\mathbf{P}$ \\
\hline Number of patients & $319(72.67 \%)$ & $120(27.33 \%)$ & - \\
\hline Mean follow-up [months] & $39.82 \pm 0.6$ & $38.12 \pm 1.1$ & 0.141 \\
\hline Age & $66.55 \pm 0.6$ & $73.53 \pm 0.8$ & $<0.001$ \\
\hline Female sex & $73(22.9 \%)$ & $31(25.8 \%)$ & 0.517 \\
\hline Hypertension & $223(69.9 \%)$ & $95(79.2 \%)$ & 0.053 \\
\hline Dyslipidemia & $201(63.0 \%)$ & $83(69.2 \%)$ & 0.229 \\
\hline Diabetes mellitus & $101(31.7 \%)$ & $61(50.8 \%)$ & $<0.001$ \\
\hline Insulin therapy & $17(5.3 \%)$ & $22(18.3 \%)$ & $<0.001$ \\
\hline Smoker (current and former) & $194(60.8 \%)$ & $57(47.5 \%)$ & 0.012 \\
\hline Previous CABG & $9(2.8 \%)$ & $3(2.5 \%)$ & $>0.999 *$ \\
\hline Previous $\mathrm{PCl}$ & $170(49.0 \%)$ & $48(52.2 \%)$ & 0.587 \\
\hline Previous MI & $157(49.2 \%)$ & $61(50.8 \%)$ & 0.763 \\
\hline Peripheral vascular disease & $18(5.6 \%)$ & $20(16.7 \%)$ & $<0.001$ \\
\hline Previous stroke & $14(4.4 \%)$ & $7(5.8 \%)$ & 0.527 \\
\hline COPD & $20(6.3 \%)$ & $10(8.3 \%)$ & 0.554 \\
\hline Statins & $287(93.8 \%)$ & $106(91.4 \%)$ & 0.382 \\
\hline ACEls/ARBs & $234(76.5 \%)$ & $89(76.7 \%)$ & 0.956 \\
\hline Beta-blockers & $243(79.4 \%)$ & $90(77.6 \%)$ & 0.682 \\
\hline Acetylsalicylic acid & $299(95.8 \%)$ & $106(89.1 \%)$ & 0.008 \\
\hline Anticoagulation & $10(6.3 \%)$ & $20(16.7 \%)$ & 0.003 \\
\hline Clinical presentation: & & & 0.451 \\
\hline Stable angina & $144(45.1 \%)$ & $59(49.2 \%)$ & \\
\hline Acute coronary syndrome & $175(54.9 \%)$ & $61(50.8 \%)$ & \\
\hline
\end{tabular}

Results are presented as number (\%) or mean ( \pm standard deviation). P values marked with asterisk $\left({ }^{*}\right)$ are calculated with Fisher's exact test. ACEls - angiotensin-converter enzyme inhibitors; ARBs - angiotensin receptor blockers; CABG - coronary artery bypass grafting; CKD chronic kidney disease; COPD — chronic obstructive pulmonary disease; eGFR - estimated glomerular filtration rate; MI - myocardial infarction; $\mathrm{PCl}$ — percutaneous coronary intervention

Outcomes in patients with and without CKD

The median follow-up was 42.1 (interquartile range [IQR] 26.6) and 43.0 (IQR 26.2) months in patients with and without CKD, respectively.

At 4 years, $30(25.0 \%)$ patients with eGFR $<60 \mathrm{~mL} / \mathrm{min} / 1.73 \mathrm{~m}^{2}$ met the primary endpoint (patient-oriented composite endpoint [POCE]: composite of all-cause death, MI, or unplanned revascularization), in comparison with $46(14.4 \%)$ patients with eGFR $>60 \mathrm{~mL} / \mathrm{min} / 1.73 \mathrm{~m}^{2}$ (Fig. 2A). The unadjusted HR was 1.81 (95\% CI 1.15-2.84; $\mathrm{p}=0.010)$. This difference was mainly driven by a higher rate of all-cause death $(13.3 \%$ vs. $5.3 \% ; \mathrm{p}=0.006)$ and cardiovascular death $(5.8 \%$ vs. $1.3 \% ; \mathrm{p}=0.012$ ), and a less prominent but also higher rate of unplanned revascularization in patients with worse renal function $(11.7 \%$ vs. $7.2 \% ; \mathrm{p}=0.097$; Table 3). No differences were observed in the incidence of MI $(4.2 \%$ vs. $4.4 \%$; $\mathrm{p}=0.967)$. The adjusted multivariate analysis failed to reach statistical significance for the primary or the secondary endpoints but showed a trend towards a higher incidence of POCE in patients with $\mathrm{eGFR}<60 \mathrm{~mL} / \mathrm{min} / 1.73 \mathrm{~m}^{2}$, with a $\mathrm{HR}$ of $1.56(95 \% \mathrm{CI} 0.96-2.53 ; \mathrm{p}=0.071)$, and towards more frequent unplanned revascularizations (HR 1.91; 95\% CI 0.93-3.93; $\mathrm{p}=0.078$ ).

Nevertheless, in the categorical analysis of the stages of CKD, the patients from stages G4 and G5 (eGFR of less than $30 \mathrm{~mL} / \mathrm{min} / 1.73 \mathrm{~m}^{2}$ ) showed a marked increase in the incidence of POCE when compared to the reference category (stage G1: eGFR $>60 \mathrm{~mL} / \mathrm{min} / 1.73 \mathrm{~m}^{2}$ ). In this case, the association remained significant in the adjusted analysis, with a HR of 3.10 (95\% CI 1.08-8.92; $\mathrm{p}=0.036$; Table 4, Fig. 2B).

Interestingly, the higher event rate observed in patients with CKD was not related with the vessel 
Table 2. Angiographic characteristics of the population.

\begin{tabular}{|c|c|c|c|}
\hline & $\begin{array}{c}\text { No CKD (eGFR > } 60 \mathrm{~mL} / \\
\left./ \mathrm{min} / 1.73 \mathrm{~m}^{2}\right)\end{array}$ & $\begin{array}{c}\text { CKD (eGFR }<60 \mathrm{~mL} / \\
\left./ \mathrm{min} / 1.73 \mathrm{~m}^{2}\right)\end{array}$ & $\mathbf{P}$ \\
\hline Number of patients & $319(72.7 \%)$ & $120(27.3 \%)$ & - \\
\hline Number of vessels & $427(73.0 \%)$ & $158(27.0 \%)$ & - \\
\hline $\begin{array}{l}\text { Mean of evaluated vessels } \\
\text { (per patient) }\end{array}$ & $1.34 \pm 0.03$ & $1.32 \pm 0.05$ & 0.990 \\
\hline \multicolumn{4}{|l|}{ Vessels evaluated per patient: } \\
\hline 1 & $230(72.1 \%)$ & $91(75.8 \%)$ & 0.432 \\
\hline 2 & $73(22.9 \%)$ & $21(17.5 \%)$ & 0.220 \\
\hline 3 & $13(4.1 \%)$ & $7(5.8 \%)$ & 0.431 \\
\hline 4 & $3(0.9 \%)$ & $1(0.8 \%)$ & $>0.999 *$ \\
\hline Percent of stenosis & $59 \pm 0.44$ & $61 \pm 0.76$ & 0.027 \\
\hline Technique for deferral: & & & 0.936 \\
\hline FFR & $251(78.7 \%)$ & $94(78.3 \%)$ & \\
\hline iFR & $68(21.3 \%)$ & $26(21.7 \%)$ & \\
\hline Mean FFR & $0.87( \pm 0.003)$ & $0.87( \pm 0.004)$ & 0.435 \\
\hline Mean iFR & $0.95( \pm 0.003)$ & $0.94( \pm 0.005)$ & 0.296 \\
\hline \multicolumn{4}{|l|}{ Vessel evaluated: } \\
\hline Left main & $19(4.5 \%)$ & $6(3.8 \%)$ & 0.729 \\
\hline LAD & $178(41.7 \%)$ & $64(40.5 \%)$ & 0.797 \\
\hline LCX & $133(31.2 \%)$ & $40(25.3 \%)$ & 0.170 \\
\hline RCA & $91(21.3 \%)$ & $43(27.2 \%)$ & 0.131 \\
\hline Ramus intermedius & $6(1.4 \%)$ & $5(3.2 \%)$ & 0.164 \\
\hline Multivessel disease ( $\geq 3$ vessels) & $60(18.8 \%)$ & $26(21.7 \%)$ & 0.501 \\
\hline
\end{tabular}

Results are presented as number $(\%)$ or mean ( \pm standard deviation). P values marked with asterisk $(*)$ are calculated with Fisher's exact test. CKD - chronic kidney disease; eGFR - estimated glomerular filtration rate; FFR - fractional flow reserve; iFR - instantaneous free-wave ratio; LAD — left anterior descendant; LCX — left circumflex artery; RCA — right coronary artery

deferred by physiological evaluation. When assessing vessel-oriented outcomes, patients with eGFR $<60$ $\mathrm{mL} / \mathrm{min} / 1.73 \mathrm{~m}^{2}$ showed similar rates of TVR $(5.8 \% \mathrm{vs}$. $5.0 \%$ in non-CKD patients) and target vessel $\mathrm{MI}(0.8 \%$ vs. $1.6 \%$ in non-CKD patients) related to the vessel left untreated on the grounds of non-ischemic FFR or iFR vales, both being non-statistically significant in the unadjusted and adjusted analysis (Fig. 2B, C).

\section{Revascularization deferral based on FFR or iFR: Influence on patient outcomes}

In the overall population, a total of $345(78.6 \%)$ patients were deferred by FFR, and 94 (21.4\%) were deferred by iFR, with a ratio between techniques similar in both groups with and without CKD $(\mathrm{p}=0.936)$. The primary endpoint occurred in $64(18.6 \%)$ patients in which the lesion was deferred by FFR, and in $12(12.8 \%)$ patients deferred by iFR, with no differences between the techniques in patients with eGFR above or below $60 \mathrm{~mL} / \mathrm{min} / 1.73 \mathrm{~m}^{2}$ (Fig. 3, Table 5). No significant differences in the incidence of other events were observed when comparing FFR and iFR deferral in patients with or without CKD.

\section{Discussion}

The main findings of the present study are as follows: i) in patients in whom revascularization of coronary stenosis has been deferred according to pressure-wire evaluation, the presence of CKD is associated with worse outcomes; ii) the excess in POCE observed in CKD patients is not caused by vessel-oriented events related to the deferred stenoses; and iii) no differences in outcomes were noted in CKD patients according to the physiological index (iFR or FFR) used in decision-making.

Overall, the findings of the study support the safety of pressure-guidewire based deferral of revascularization in patients with CKD, while highlighting the overall higher cardiovascular risk and worse prognosis of these patients, compared with those with normal renal function. 

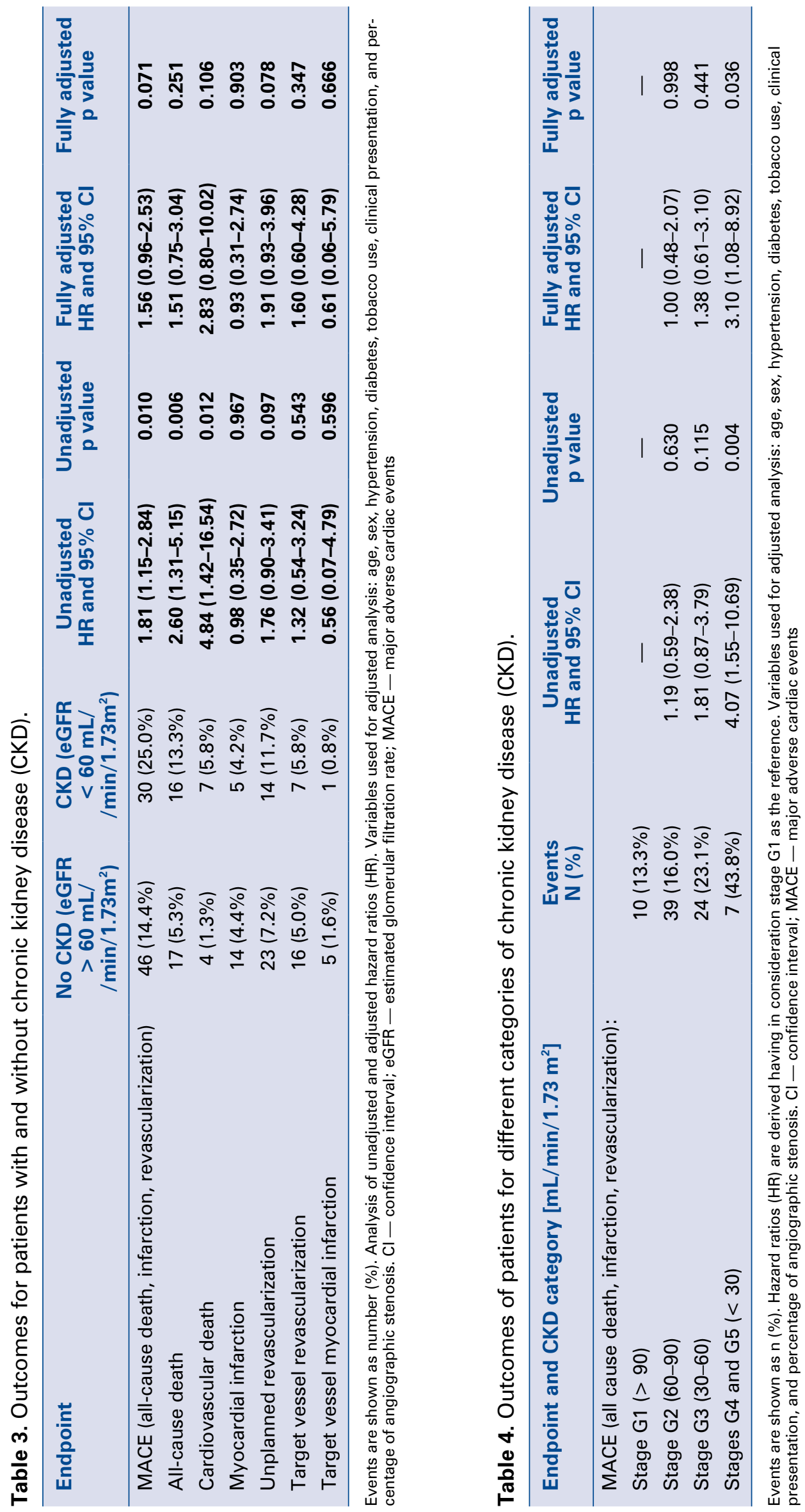


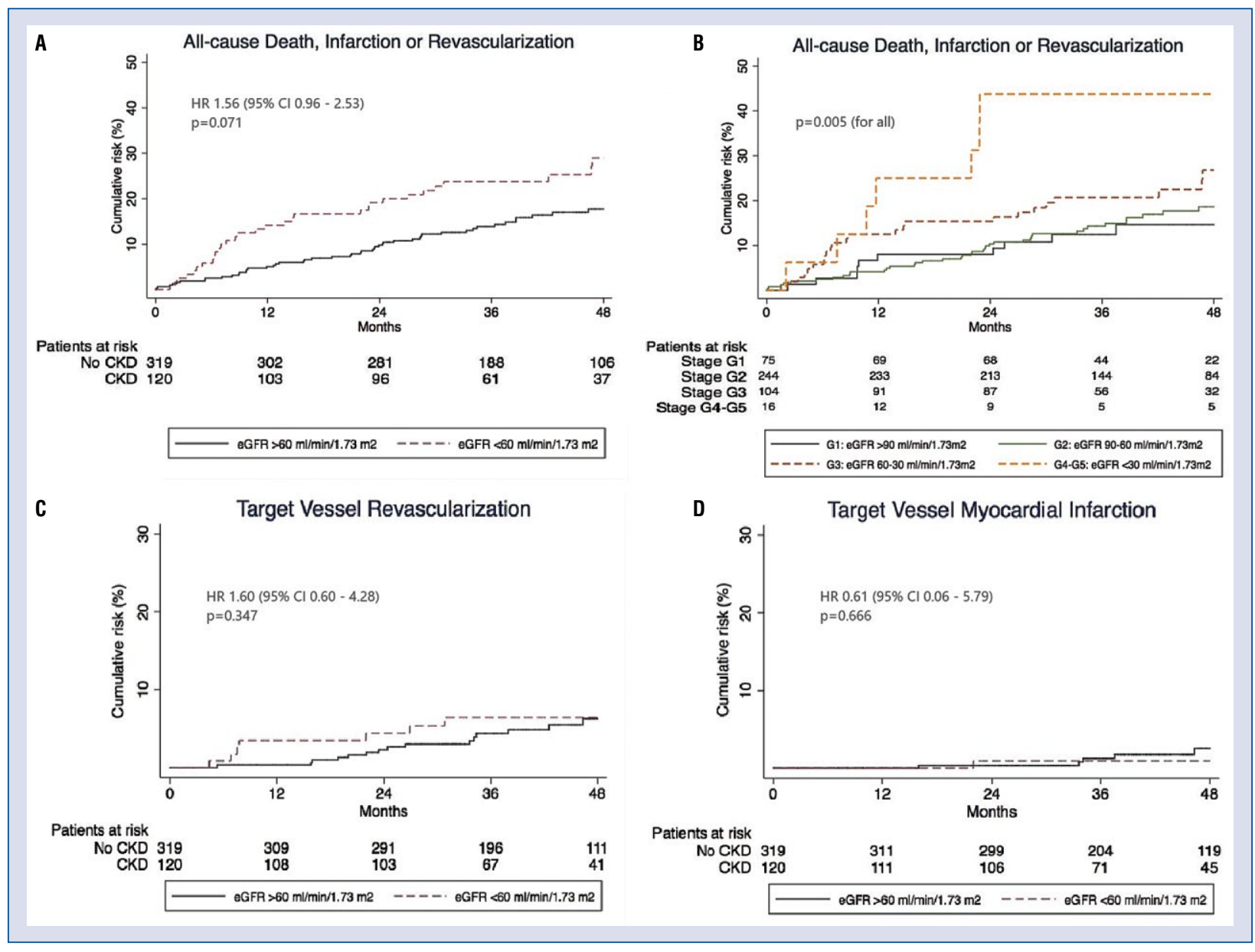

Figure 2. Kaplan-Meier survival plots comparing outcomes according to the presence or not of chronic kidney disease (CKD), and across CKD stages; A. Cumulative incidence of the primary endpoint (all-cause death, infarction, or unplanned revascularization) for the dichotomous variable CKD; B. Incidence of the primary endpoint for the different CKD stages; C. Incidence of target vessel revascularization for patients with or without CKD; D. Incidence of target vessel myocardial infarction; $\mathrm{Cl}$ - confidence interval; eGFR - estimated glomerular filtration rate; HR - hazard ratio. For the individual HR of the different CKD categories (plot B), see Table 4.

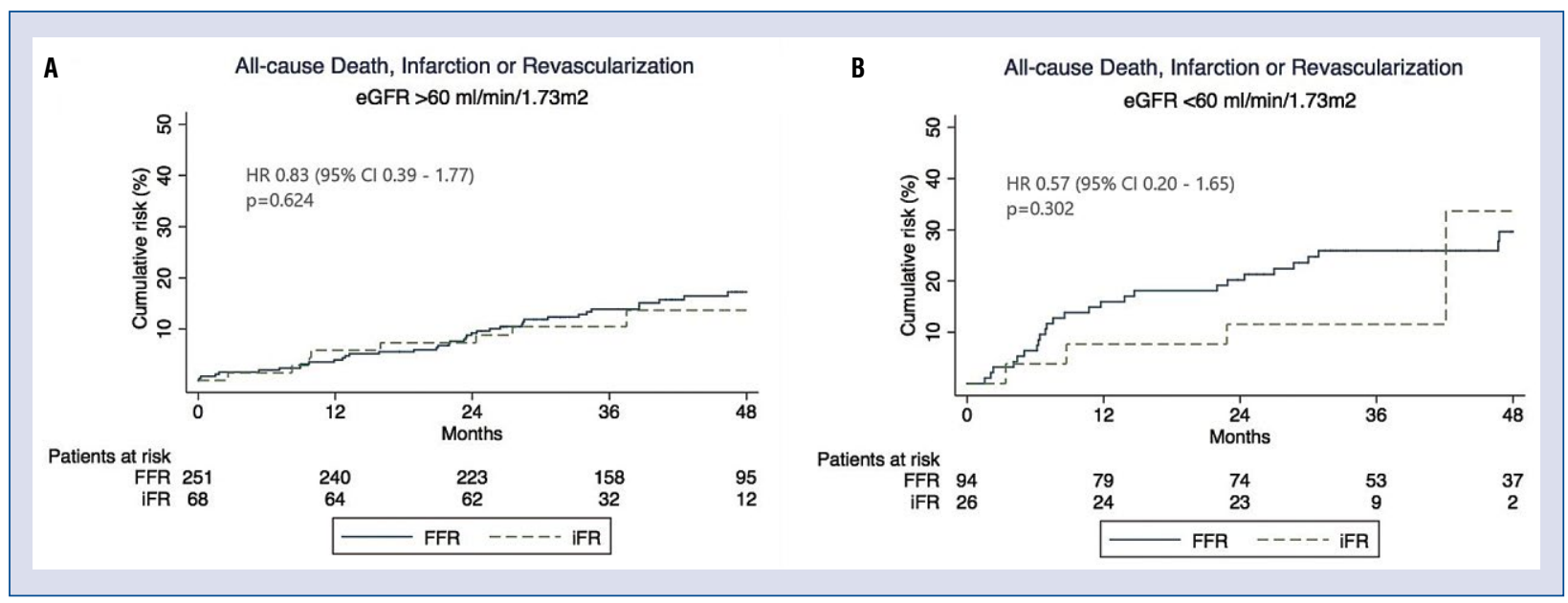

Figure 3. Kaplan-Meier survival plots comparing the technique used for revascularization deferral; A. Cumulative incidence of the primary endpoint in patients without chronic kidney disease (CKD) (estimated glomerular filtration rate [eGFR] $>60 \mathrm{~mL} / \mathrm{min} / 1.73 \mathrm{~m}^{2}$ ) according to the technique of physiological assessment used (fractional flow reserve [FFR] or instantaneous wave-free ratio [iFR]); B. Cumulative incidence of the primary endpoint in patients with CKD (eGFR $<60 \mathrm{~mL} / \mathrm{min} / 1.73 \mathrm{~m}^{2}$ ); $\mathrm{Cl}$ - confidence interval; $\mathrm{HR}$ - hazard ratio. 
Table 5. Outcomes for patients according to the technique of pressure wire used to defer treatment and the presence or absence of chronic kidney disease.

\begin{tabular}{|c|c|c|c|c|}
\hline Endpoint & FFR deferred & iFR deferred & $\mathrm{HR}$ and $95 \% \mathrm{Cl}$ & $\mathbf{P}$ \\
\hline MACE (death, MI, or revascularization): & $64(18.6 \%)$ & $12(12.8 \%)$ & $0.73(0.39-1.35)$ & 0.310 \\
\hline$>60 \mathrm{~mL} / \mathrm{min} / 1.73 \mathrm{~m}^{2}$ & $38(15.1 \%)$ & $8(11.8 \%)$ & $0.83(0.39-1.77)$ & 0.624 \\
\hline$<60 \mathrm{~mL} / \mathrm{min} / 1.73 \mathrm{~m}^{2}$ & $26(27.7 \%)$ & $4(15.4 \%)$ & $0.57(0.20-1.65)$ & 0.302 \\
\hline All-cause mortality: & $25(7.3 \%)$ & $8(8.5 \%)$ & $1.30(0.59-2.89)$ & 0.519 \\
\hline$>60 \mathrm{~mL} / \mathrm{min} / 1.73 \mathrm{~m}^{2}$ & $12(4.8 \%)$ & $5(7.4 \%)$ & $1.67(0.59-4.76)$ & 0.333 \\
\hline$<60 \mathrm{~mL} / \mathrm{min} / 1.73 \mathrm{~m}^{2}$ & $13(13.8 \%)$ & $3(11.5 \%)$ & $0.94(0.27-3.33)$ & 0.925 \\
\hline Cardiovascular mortality: & $8(2.3 \%)$ & $3(3.2 \%)$ & $1.48(0.39-5.59)$ & 0.729 \\
\hline$>60 \mathrm{~mL} / \mathrm{min} / 1.73 \mathrm{~m}^{2}$ & $2(0.8 \%)$ & $2(2.9 \%)$ & $4.15(0.58-29.60)$ & 0.156 \\
\hline$<60 \mathrm{~mL} / \mathrm{min} / 1.73 \mathrm{~m}^{2}$ & $6(6.4 \%)$ & $1(3.9 \%)$ & $0.62(0.07-5.16)$ & 0.659 \\
\hline MI: & $16(4.7 \%)$ & $3(3.2 \%)$ & $0.87(0.25-3.00)$ & 0.822 \\
\hline$>60 \mathrm{~mL} / \mathrm{min} / 1.73 \mathrm{~m}^{2}$ & $12(4.8 \%)$ & $2(2.9 \%)$ & $0.74(0.16-3.30)$ & 0.690 \\
\hline$<60 \mathrm{~mL} / \mathrm{min} / 1.73 \mathrm{~m}^{2}$ & $4(4.3 \%)$ & $1(3.9 \%)$ & $1.36(0.14-12.88)$ & 0.792 \\
\hline Revascularization: & $33(9.6 \%)$ & $4(4.3 \%)$ & $0.48(0.17-1.35)$ & 0.161 \\
\hline$>60 \mathrm{~mL} / \mathrm{min} / 1.73 \mathrm{~m}^{2}$ & $20(8.0 \%)$ & $3(4.4 \%)$ & $0.61(0.18-2.05)$ & 0.421 \\
\hline$<60 \mathrm{~mL} / \mathrm{min} / 1.73 \mathrm{~m}^{2}$ & $13(13.8 \%)$ & $1(3.9 \%)$ & $0.28(0.04-2.16)$ & 0.223 \\
\hline TVR: & $21(6.1 \%)$ & $2(2.1 \%)$ & $0.39(0.09-1.71)$ & 0.216 \\
\hline$>60 \mathrm{~mL} / \mathrm{min} / 1.73 \mathrm{~m}^{2}$ & $14(5.6 \%)$ & $2(2.9 \%)$ & $0.62(0.14-2.75)$ & 0.533 \\
\hline$<60 \mathrm{~mL} / \mathrm{min} / 1.73 \mathrm{~m}^{2}$ & $7(7.5 \%)$ & $0(0 \%)$ & - & - \\
\hline Target vessel MI: & $4(1.2 \%)$ & $2(2.1 \%)$ & $2.57(0.46-14.24)$ & 0.280 \\
\hline$>60 \mathrm{~mL} / \mathrm{min} / 1.73 \mathrm{~m}^{2}$ & $3(1.2 \%)$ & $2(2.9 \%)$ & $3.48(0.58-21.03)$ & 0.175 \\
\hline$<60 \mathrm{~mL} / \mathrm{min} / 1.73 \mathrm{~m}^{2}$ & $1(1.1 \%)$ & $0(0 \%)$ & - & - \\
\hline
\end{tabular}

Events are shown as number (\%). $\mathrm{Cl}$ — confidence interval; FFR — fractional flow reserve; HR - hazard ratio; iFR - instantaneous wave-free ratio; MACE — major adverse cardiac events $\mathrm{MI}$ - myocardial infarction; TVR — target vessel revascularization

Chronic kidney disease is an independent risk factor for coronary atherosclerosis and cardiovascular disease $[9,12]$. Although impairment of renal function is associated with worse outcomes after myocardial revascularization [13, 14], the causes for this increased event rate are unclear. As stated in the introduction, there is a paucity of data on whether physiology-guided revascularization might contribute to better outcomes of CKD patients by avoiding unneeded interventions. Patients with CKD were underrepresented in pivotal studies supporting the value of FFR and iFR. In the FAME and FAME II trials no exclusion criteria were established based on renal function, but in the latter, the prevalence of defined CKD was less than $3 \%$ in the overall population.

From a theoretical standpoint, it might be possible that the diagnostic yield of both FFR and iFR is impaired in patients with CKD. Endothelial and microvascular dysfunction are common features of CKD, leading to impaired coronary vasodilator capacity [15] and higher microcirculatory resistances [16]. Coronary vasodilator dysfunction is an independent predictor of mortality in patients with CKD [17], with incremental diagnostic power over clinical assessment, left ventricular systolic function, and the presence of ischemia or non-viable myocardium. Due to this, the use of hyperemicdependent diagnostic methods may be inadequate in establishing the true hemodynamic significance of coronary stenoses in CKD patients. On the other hand, iFR has demonstrated a closer correlation with coronary flow reserve (CFR) values than FFR. Because CFR is predictive of the risk of cardiovascular death regardless of CKD stage [18], it remains plausible that decision-making with FFR and iFR might be associated with differences in patient outcomes.

Few studies have focused on the use of physiology-based coronary indices in CKD patients. Tebaldi et al. [16] found that patients with CKD were more likely to have non-ischemic values of $\mathrm{FFR}$, this being more frequent as renal function worsens. Conversely, a short report $(n=42)$ on hemodialysis patients [19] showed that the optimal cut-off value of FFR for detection of myocardial 
ischemia (assessed with stress myocardial perfusion imaging techniques) was similar to the cut-off value in the overall population. However, because those studies were transversal in nature and lacked clinical follow-up of their study populations, the clinical impact of an FFR-based treatment strategy remains unknown.

In our study, we observed that patients with an eGFR of less than $60 \mathrm{~mL} / \mathrm{min} / 1.73 \mathrm{~m}^{2}$ had a higher incidence of the primary endpoint (all-cause death, MI, or unplanned revascularization) when compared to patients with preserved renal function. Although in the adjusted analysis this association was not statistically significant, we could observe a trend $(\mathrm{p}=0.071)$. This conclusion is further supported by the gradient effect that was observed in the staged analysis: as the renal function worsens, the incidence of POCE increases. We observed a 5\% annual risk of POCE in the population with $\mathrm{CKD}$, in contrast with a $3.6 \%$ annual risk in the non-CKD population. Both are comprised within the upper and lower limits of the incidence of 1-year major cardiovascular events estimated in previous studies of pressure wire-deferred vessels $[6,20]$.

This difference of POCE between CKD and non-CKD patients was mainly caused by an augmented risk of all cause death, cardiac death, and unplanned revascularizations, the incidence of MI being similar in both groups.

What is more relevant, even with this greater incidence of POCE and higher prevalence of comorbidities, there were no significant differences in vessel-oriented events (TVR or target vessel MI) related to the coronary artery interrogated with iFR or FFR. This supports our conclusion that, although patients with CKD are at high-risk for the development of cardiovascular events, deferring lesions according to pressure wire values is safe in terms of the incidence of MI or the necessity of unplanned revascularization in the evaluated vessel. In practice, at 4 years of follow-up, only half of the total amount of revascularizations in patients with renal insufficiency were performed in the previously interrogated vessel, in contrast with $69 \%$ in the non-CKD population. Furthermore, in CKD patients only 1 out of every 5 MIs during follow-up was attributable to the vessel assessed. Overall, these observations might reflect a wider progression of the disease in patients with CKD, not restricted to the vessel evaluated with pressure wire, and this leads to events related with other areas of the coronary tree.

In the sub-analysis regarding the technique used for physiological assessment, we conclude that, despite obvious limitations, the use of iFR to defer the treatment of intermediate coronary stenosis is associated with similar outcomes to those with the use of FFR, irrespective of the presence or absence of renal insufficiency. However, in this cohort the decision of whether to perform iFR or FFR was at the operator's discretion, and therefore we cannot exclude the occurrence of selection bias. Additionally, the sample number did not provide enough power to compare both techniques in different CKD stages. In order to precisely address the potential role of non-hyperemic indexes against FFR in more advanced renal insufficiency, a randomized study between both techniques is needed.

\section{Limitations of the study}

This study has various limitations. First, it is a single-center, retrospective, and observational study, and even if the results appear to be consistent, they should be considered as hypothesis-generating until further prospective randomized data becomes available. Second, eGFR estimated via creatinine levels could not be a reliable estimator of the baseline renal function in some cases. Although operators are discouraged to perform coronary angiography in the setting of acute renal failure, there was no previous data in order to exclude patients with recent worsening of eGFR. Third, the absence of randomization could have led to involuntary patient selection, avoiding the realization of angiography in patients with worse renal function. Fourth, because of the reduced number of patients with more severe CKD (eGFR $<30 \mathrm{~mL} / \mathrm{min} / 1.73 \mathrm{~m}^{2}$ ), conclusions regarding secondary outcomes or the comparison between iFR and FFR in this subgroup were not feasible due to the lack of statistical power. And fifth, because FFR, iFR, and eGFR are continuous variables, the dichotomization in cut-off points always involves the loss of potentially relevant data. Limitations regarding comparison of FFR and iFR have been previously discussed.

On the other hand, our study provides real-world information about outcomes in daily practice, and the results mentioned above can fuel future investigations that will help to elucidate the best therapeutic strategies in CKD patients.

\section{Conclusions}

Patients with CKD and coronary lesions deferred upon pressure-wire evaluation have a higher risk of POCE than those with normal renal function, but these events are not related to the de- 
ferred vessel. Pressure-wire evaluation is safe in terms of the risk of target vessel revascularization or target vessel MI in this population.

Conflict of interest: Dr. Travieso-Gonzalez, Dr. Casto-Mejia, Dr. Jeronimo-Baza, Dr. Perez-Vizcayno, Dr. Mejia-Rentería, Dr. Macaya, Dr. Tirado-Conte, Dr. Jimenez-Quevedo, Dr. Salinas, and Dr. Nuñez-Gil do not have disclosures. Dr. Nombela-Franco has served as proctor for Abbott and has received speaker honoraria from Edwards Lifesciences. Dr. Fernandez-Ortiz is a speaker at educational events funded by Medtronic, Biotronik, Biosensor, and Bayer. Dr. Escaned is a speaker and consultant for Abbott, Boston Scientific, and Phillips and has received personal fees from Phillips Volcano, Boston Scientific, and Abbott/St. Jude Medical. Dr. Gonzalo is a speaker at educational events funded by Abbott and Boston Scientific.

\section{References}

1. Tonino PAL, De Bruyne B, Pijls NHJ, et al. Fractional flow reserve versus angiography for guiding percutaneous coronary intervention. N Engl J Med. 2009; 360(3): 213-224, doi: 10.1056/ NEJMoa0807611, indexed in Pubmed: 19144937.

2. Davies JE, Sen S, Dehbi H-M, et al. Use of the Instantaneous Wave-free Ratio or Fractional Flow Reserve in PCI. N Engl J Med. 2017; 376: 1824-1834.

3. Götberg M, Christiansen EH, Gudmundsdottir IJ, et al. Instantaneous Wave-free Ratio versus Fractional Flow Reserve to Guide PCI. N Engl J Med. 2017; 376(19): 1813-1823, doi: 10.1056/ NEJMoa1616540, indexed in Pubmed: 28317438.

4. Lee HS, Lee JM, Nam CW, et al. Consensus document for invasive coronary physiologic assessment in Asia-Pacific countries. Cardiol J. 2019; 26(3): 215-225, doi: 10.5603/CJ.a2019.0054, indexed in Pubmed: 31225632.

5. Bech GJ, De Bruyne B, Pijls NH, et al. Fractional flow reserve to determine the appropriateness of angioplasty in moderate coronary stenosis: a randomized trial. Circulation. 2001; 103(24): 2928-2934, doi: 10.1161/01.cir.103.24.2928, indexed in Pubmed: 11413082.

6. Escaned J, Ryan N, Mejía-Rentería H, et al. Safety of the deferral of coronary revascularization on the basis of instantaneous wave-free ratio and fractional flow reserve measurements in stable coronary artery disease and acute coronary syndromes. JACC Cardiovasc Interv. 2018; 11(15): 1437-1449, doi: 10.1016/j. jcin.2018.05.029, indexed in Pubmed: 30093050.

7. Sugiyama T, Kimura S, Ohtani H, et al. Impact of chronic kidney disease stages on atherosclerotic plaque components on optical coherence tomography in patients with coronary artery disease. Cardiovasc Interv Ther. 2017; 32(3): 216-224, doi: 10.1007/ s12928-016-0408-y, indexed in Pubmed: 27339299.
8. Bundy JD, Chen J, Yang W, et al. Risk factors for progression of coronary artery calcification in patients with chronic kidney disease: The CRIC study. Atherosclerosis. 2018; 271: 53-60, doi: 10.1016/j.atherosclerosis.2018.02.009, indexed in Pubmed: 29459266.

9. Go AS, Chertow GM, Fan D, et al. Chronic kidney disease and the risks of death, cardiovascular events, and hospitalization. N Engl J Med. 2004; 351(13): 1296-1305, doi: 10.1056/NEJMoa041031, indexed in Pubmed: 15385656.

10. Fried LF, Shlipak MG, Crump C, et al. Renal insufficiency as a predictor of cardiovascular outcomes and mortality in elderly individuals. J Am Coll Cardiol. 2003; 41(8): 1364-1372, doi: 10.1016/s0735-1097(03)00163-3, indexed in Pubmed: 12706933.

11. Levey AS, Coresh J, Bolton K, et al. K/DOQI clinical practice guidelines for chronic kidney disease: Evaluation, classification, and stratification. Am J Kidney Dis. 2002; 39: S1-S266.

12. Pereg D, Tirosh A, Shochat T, et al. Mild renal dysfunction associated with incident coronary artery disease in young males. Eur Heart J. 2008; 29(2): 198-203, doi: 10.1093/eurheartj/ehm525, indexed in Pubmed: 18079138.

13. Milojevic M, Head SJ, Mack MJ, et al. The impact of chronic kidney disease on outcomes following percutaneous coronary intervention versus coronary artery bypass grafting in patients with complex coronary artery disease: five-year follow-up of the SYNTAX trial. EuroIntervention. 2018; 14(1): 102-111, doi: 10.4244/EIJ-D-17-00620, indexed in Pubmed: 29155387.

14. Best $\mathrm{P}$, Lennon $\mathrm{R}$, Ting $\mathrm{H}$, et al. The impact of renal insufficiency on clinical outcomes in patients undergoing percutaneous coronary interventions. J Am Coll Cardiol. 2002; 39(7): 1113-1119, doi: 10.1016/s0735-1097(02)01745-x.

15. Chade AR, Brosh D, Higano ST, et al. Mild renal insufficiency is associated with reduced coronary flow in patients with non-obstructive coronary artery disease. Kidney Int. 2006; 69(2): 266-271, doi: 10.1038/sj.ki.5000031, indexed in Pubmed: 16408115.

16. Tebaldi M, Biscaglia S, Fineschi M, et al. Fractional Flow Reserve Evaluation and Chronic Kidney Disease: Analysis From a Multicenter Italian Registry (the FREAK Study). Catheter Cardiovasc Interv. 2016; 88(4): 555-562, doi: 10.1002/ccd.26364, indexed in Pubmed: 26717890.

17. Murthy VL, Naya M, Foster CR, et al. Coronary vascular dysfunction and prognosis in patients with chronic kidney disease. JACC Cardiovasc Imaging. 2012; 5(10): 1025-1034, doi: 10.1016/j.jcmg.2012.06.007, indexed in Pubmed: 23058070.

18. Charytan DM, Skali H, Shah NR, et al. Coronary flow reserve is predictive of the risk of cardiovascular death regardless of chronic kidney disease stage. Kidney Int. 2018; 93(2): 501-509, doi: 10.1016/j.kint.2017.07.025, indexed in Pubmed: 29032954.

19. Hirose K, Chikamori T, Hida S, et al. Application of pressurederived myocardial fractional flow reserve in chronic hemodialysis patients. J Cardiol. 2018; 71(1): 52-58, doi: 10.1016/j. jjcc.2017.05.007, indexed in Pubmed: 29183566.

20. Sen S, Ahmad Y, Dehbi HM, et al. Clinical events after deferral of LAD revascularization following physiological coronary assessment. J Am Coll Cardiol. 2019; 73(4): 444-453, doi: 10.1016/j. jacc.2018.10.070, indexed in Pubmed: 30704577. 